\title{
Álcool, direção automotiva e o Programa Vida Urgente na visão de jovens voluntários
}

\author{
Andréa dos Santos Nascimento1 - Universidade Federal do Espírito Santo, Vitória, Brasil \\ Davi Mañini Macedo - Universidade Federal do Espirito Santo, Vitória, Brasil \\ Julia Carolina Rafalski - Universidade Federal do Espírito Santo, Vitória, Brasil \\ Lorena Dias de Abreu - Universidade Federal do Espirito Santo, Vitória, Brasil \\ Mayara Gama de Lima - Universidade Federal do Espírito Santo, Vitória, Brasil
}

\begin{abstract}
Resumo
O objetivo deste estudo é analisar as representações sociais dos jovens voluntários do Programa Vida Urgente, do Espírito Santo, acerca do trabalho por eles realizado. Foram realizadas 20 entrevistas com roteiro semiestruturado objetivando conhecer a opinião sobre os efeitos da própria atuação e a visão que possuem do programa. Para tanto foram entrevistados jovens de ambos os sexos, com idades entre 15 e 26 anos, posteriormente divididos em dois grupos com base no critério de tempo de atuação nas ações do Programa: G1 - 06 a 12 meses e G2 - acima de 12 meses. Por meio da análise de conteúdo, verificou-se que a afinidade com a proposta do trabalho voluntário e a valorização do discurso da conscientização são alguns dos motivos para o ingresso no Programa. Os entrevistados informaram ter identificado maior receptividade no público-alvo, o que é percebido por eles como uma mudança positiva no comportamento dos motoristas abordados.

Palavras-chave: Álcool, Representações sociais, Psicologia social.
\end{abstract}

Vida Urgente Program, alcohol and driving: young volunteers' view

\begin{abstract}
This study's goal is to analyze the social representations of the young volunteers of Vida Urgente Program of Espírito Santo about the work developed by them. 20 interviews were carried out using a semi-structured questionnaire with the objective to know the opinion about the effects of their performance and the vision they possess about the program. For such, 20 participants of both sexes with ages from 15 to 26 years were interviewed, subsequently divided into two groups according to the time of participation in the Program: G1 - 06 to 12 months and G2 - above 12 months. Using content analysis, it was verified that the affinity with the program's proposal of volunteer work and valorization of the speech of awareness are some of the reasons to enter the program. The respondents informed having identified larger receptivity from the target-public, which is perceived by them as a positive change on approached drivers.
\end{abstract}

Keywords: Alcohol, Social representations, Social psychology.

A associação entre álcool e direção tem se tornado foco de discussão em diferentes níveis da estrutura social contemporânea, seja no âmbito da saúde coletiva, seja no da epidemiologia, educação, fiscalização, legislação. São várias as formas de intervenção que buscam prevenir e coibir o motorista de assumir a direção de veículos automotivos após a ingestão de bebidas alcoólicas. Além de a combinação entre álcool e direção automotiva ser responsável por prejuízos na esfera socioeconômica, é valido atentar para a relevância dos prejuízos causados também nos âmbitos mais específicos, como o familiar e $\mathrm{o}$ individual.

Sobre as drogas lícitas, considera Masur (2004) que "o álcool é a droga mais disponível para o consumo entre as drogas disponíveis no mercado. É um produto de baixo custo de produção e que independe da região para sua fabricação" (p. 93). O álcool é considerado por muitos um companheiro de eventos sociais, responsável pela diminuição das inibições e

${ }^{1}$ Endereço para correspondência:

E-mail: andreanas@gmail.com

Agradecemos aos participantes e ao Programa Vida Urgente que se dispuseram a colaborar com nossa pesquisa. consequente relaxamento, produzindo sensações de bem-estar no indivíduo. De acordo com Stronach (2004), em muitos casos, seu consumo implica riscos relativamente baixos, tanto para quem bebe como para quem não bebe. Em momentos de descontração e interação social, a facilidade ao acesso, o prazer em consumir, o baixo índice de prejuízo ao organismo em curto prazo e os efeitos fisiológicos do álcool quando ingerido são exemplos de fatores que favoreceram a preferência pela bebida alcoólica. Entretanto, é inegável o envolvimento do consumo de álcool em prejuízos à estrutura social.

Depois do tabaco, o álcool é a segunda maior causa de mortes relacionadas a drogas. Na maioria dos paises, o álcool tem um impacto ainda maior em termos de mortes, ferimentos e custos econômicos se comparado com as drogas ilícitas. $O$ álcool tem impactos em qualquer estágio de doença, em todos os grupos etários, de maneira direta e indireta. Toda política abrangente e significativa de saúde pública deve ter como prioridade maior a mudança das quantidades de álcool consumidas, dos padrões de consumo e dos danos subseqüentes (Stronach, 2004, p. 29).

No Brasil do século XIX, por motivos médico-higienistas, o consumo de álcool foi associado 
a doenças e a comportamentos socialmente condenáveis, como a vadiagem e a ociosidade. Era, ainda, responsável por elevados gastos do dinheiro público com a construção de instituições para abrigar a população dos ditos “degenerados" (Matos, 2000).

Cronologicamente, o percurso do consumo de álcool e as discussões que este suscita no interior do aparelho estatal foram extensos até a sua atual associação com a subsequente direção automobilística, que se configura como uma questão que ocupa espaço de destaque na política pública brasileira. Analisar as mudanças observadas na legislação que permeia o assunto é, portanto, fundamental para a compreensão dos modos como a questão tem sido abordada historicamente no país e qual é sua repercussão na atualidade.

Assim, segundo Nascimento e Garcia (2009), o Código Nacional de Trânsito que vigorou no país de 1966 a 1997 é um exemplo de que, apesar de o assunto encontrar-se em pauta, havia graves falhas em sua formulação: definia, por exemplo, que o limite máximo de concentração de álcool no sangue era de $0,8 \mathrm{~g} / \mathrm{l}$; entretanto, não estabelecia punições para aqueles que descumprissem esse limite. Apenas em 1998, com o Código de Trânsito Brasileiro (CBT), foram estabelecidas punições para condutores que apresentassem uma concentração de álcool no sangue igual ou superior a $0,6 \mathrm{~g} / 1$, tais como multa, apreensão da Carteira Nacional de Habilitação (CHN) e retenção do veículo, além de uma pontuação no prontuário do condutor equivalente a 7 (sete) pontos.

Somente em 2006, o Conselho Nacional de Trânsito (CONTRAN) por meio da Resolução 206, demarcou os requisitos necessários para a detecção de substâncias psicoativas no organismo humano, assim como o procedimento a ser adotado por autoridades e agentes de trânsito. A comprovação de que o motorista encontra-se alcoolizado ocorre por meio de teste de alcoolemia que comprove concentração de álcool na corrente sanguínea maior ou igual a $0,6 \mathrm{~g} / 1$, ou por meio de teste em aparelho de ar alveolar pulmonar (popularmente conhecido como "bafômetro"), que acuse concentração de álcool igual ou superior a 0,3 miligramas por litro de ar expelido dos pulmões (Brasil, 2006). Outras ferramentas podem ser utilizadas na constatação da embriaguez alcoólica, como laudos conclusivos por médico examinador da Polícia Judiciária, exames realizados por laboratórios especializados ou outras provas obtidas pelo agente da autoridade de trânsito acerca dos sinais resultantes do consumo de álcool ou de qualquer substância entorpecente apresentados pelo condutor, caso este se recuse a realizar qualquer um dos testes supracitados (Brasil, 2006).
Outro marco no Código de Trânsito Brasileiro surge dois anos depois, quando foi sancionada, em junho de 2008, a Lei 11.705, apelidada de "Lei Seca", com o intuito de diminuir, de maneira objetiva, as consequências do consumo de substâncias alcoólicas e sequente direção automotiva. De acordo com as diretrizes da nova lei, o motorista que for flagrado dirigindo sob a influência de álcool ou de qualquer outra substância psicoativa terá sua $\mathrm{CNH}$ suspensa por um período de doze meses, sujeitar-se-á ao pagamento de multa equivalente ao valor de $\mathrm{R} \$ 957,70$, além de ter o veículo retido até a apresentação de condutor habilitado. O nível de alcoolemia permitido no sangue é de 0 gramas por litro, embora exista, na prática, uma relativa tolerância $(0,2 \mathrm{~g} / 1$ de sangue ou $0,1 \mathrm{mg}$ de álcool por litro de ar expelido durante o exame do bafômetro), que prevê casos excepcionais, como o uso de medicamentos a base de álcool e erros na aparelhagem utilizada para a realização dos testes (Brasil, 2008).

Uma das estratégias que figuram como principais na intervenção da problemática aqui discutida é a Política de Redução de Danos. De acordo com Stronach (2004), essa prática consiste em políticas que promovam uma redução das consequências biopsicossociais negativas do consumo de drogas não somente para o usuário, mas também para sua família e comunidade. Tal abordagem pode ser utilizada tanto em relação às drogas lícitas quantas ilícitas. A Política de Redução de Danos, em sua relação com o consumo abusivo do álcool, busca complementar ações sem necessariamente proibir o consumo da bebida: "Considerando que o consumo de álcool irá continuar, e que o abuso de álcool também, os princípios e estratégias de redução de danos são lógicos e comprovadamente eficientes" (Stronach, 2004, p. 33).

Ainda segundo Stronach (2004), desafios reais apresentam-se quando se busca implementar políticas para a redução de comportamentos observados pelo consumo abusivo de bebida alcoólica, mesmo que tais medidas estejam focadas na atenuação das consequências e não na repressão do comércio em si. Esse fenômeno esbarra, por exemplo, em aspectos culturais, como a representação social vinculada à imagem do consumo de bebida alcoólica que é considerado como indicador de independência, liberdade ou poder, principalmente entre os mais jovens.

No âmbito da Teoria das Representações Sociais, o social é considerado uma estrutura peculiar que não diz respeito apenas à soma de seus elementos individuais. Jodelet (2001) conceitualiza o termo Representações Sociais da seguinte maneira: "Uma forma de conhecimento, socialmente elaborada e 
partilhada, tendo uma visão prática e concorrendo para a construção de uma realidade comum a um conjunto social". A partir daí, quando pensamos na prática de representação social, é preciso ter atenção ao fato de que esta é, a todo o tempo, legitimada, reconstruída, retocada socialmente. Em Jovchelovitch (1994), encontramos a importância da comunicação e das práticas sociais, como o "diálogo, discurso, rituais, padrões de trabalho e produção, arte, em suma, cultura" (p. 79) nesse processo de (re)construção e manutenção das representações. O social deve ser analisado enquanto "totalidade" (p. 79). A autora destaca a importância dos processos de mediação social, mediação entre diferentes perspectivas, entre o mundo que se ergue ao nosso redor e nossa necessidade de conhecê-lo, explicá-lo; é essa mediação que, em suas mais diversas formas, gera as representações sociais:

As representações sociais são uma estratégia desenvolvida por atores sociais para enfrentar a diversidade e a mobilidade de um mundo que, embora pertença a todos, transcende a cada um individualmente. Nesse sentido, elas são um espaço potencial de fabricação comum, onde cada sujeito vai além de sua própria individualidade para entrar em dominio diferente, ainda que fundamentalmente relacionado: o dominio da vida em comum, o espaço público. (Jovchelovitch, 1994, p. 81)

Nesse contexto, é interessante descobrir como as pessoas constroem seus saberes, valores e conceito e como os expressam na sociedade, e para isso não se pode descartar o papel que a mídia tem no âmbito das representações sociais, mesmo que aquela não crie estas. No caso das políticas de prevenção ao abuso de álcool, a mídia se torna um instrumento eficiente e de amplo alcance, que irá, em maior ou menor grau, agregar valor e conhecimento ao contexto, podendo tornar a questão do álcool e direção automotiva, para além da agenda pública, uma questão no contexto popular com valor positivo ou negativo.

Segundo Nascimento e Garcia (2009, p. 216),

Cabe aqui destacar o papel da mídia nesse processo, um papel relevante na agenda governamental e na constituição da opinião pública. A mídia constitui-se em forma de funcionamento da comunicação de massa (mass media), que traz muitas informações em pouco tempo. Funciona como um catalizador e até dissipador de impactos causados por ela mesma na população, contribuindo para que certas questões (issues) entrem na agenda e permaneçam nela, (Nascimento e Garcia, 2009, p. 216)

E nessa inter-relação entre políticas públicas, mídia, representações e comportamentos, observam-se tentativas do poder público em prevenir o consumo de álcool por motoristas. Diferentes atuações do poder público têm demonstrado eficácia em provocar mudanças no comportamento dos consumidores de bebida alcoólica quanto a dirigir após o consumo dessas. Nessa esfera, enquadram-se as atividades desenvolvidas pelo Programa Vida Urgente, de Vitória (ES), cujo trabalho de conscientização é desenvolvido por jovens voluntários e tem como público-alvo, sobretudo, jovens da mesma faixa etária.

A Fundação Thiago de Moraes Gonzaga foi criada em 13 de maio de 1996 pelos pais de Thiago, um jovem que, aos 18 anos, faleceu em um acidente de trânsito, em Porto Alegre (Fundação Thiago de Moraes Gonzaga, s. d.). O Programa Vida Urgente, uma das estratégias de atuação da Fundação, foi lançado no mesmo ano, com a finalidade de realizar ações de preservação e valorização da vida no trânsito.

No ano de 2008, 12 anos após a sua criação, o Governo do Estado do Espírito Santo, por meio do DETRAN, inaugurou em Vitória o Espaço Vida Urgente Espírito Santo. Para tanto, diversos jovens são convidados para atuarem voluntariamente como agentes de conscientização para a prevenção dos acidentes de trânsito causados pela combinação entre álcool e direção automotiva.

Após um período de treinamento, esses jovens atuam em diversos seguimentos do programa Vida Urgente. Um deles é o Vida Urgente no Rock, no qual uma van com cerca de 15 jovens percorre alguns bairros com grande concentração de bares e abordam pesssoas de diferentes faixas etárias com discursos de educação, conscientização e apelo para a problemática álcool e trânsito. Outra ação, que só é permitida aos jovens maiores de 18 anos, consiste em acompanhar o Programa Madrugada Viva; atuando no que se pode compreender como uma "fase educativa", esses voluntários abordam motoristas cuja taxa de alcoolemia constatada foi zero, como que os congratulando pelo comportamento exemplar.

Para a Fundação, a questão do trânsito vai além de um mero problema na segurança ou transporte, portanto, deve-se atentar para a educação e até mesmo para os impactos dos acidentes de trânsito na saúde pública. Para eles, só se tornará possível uma mudança cultural e comportamental a médio e longo prazo, por meio de um trabalho de conscientização via educação (Fundação Thiago de Moraes Gonzaga, s. d.).

Por meio de ações práticas de caráter educativo, o Programa Vida Urgente objetiva, principalmente, tornar o trânsito mais seguro no país. Seus membros continuamente ressaltam que esta não é apenas uma campanha de trânsito, mas, principalmente, um programa de valorização e 
preservação da vida, pontos-chave para o entendimento da Fundação. Para tanto, afirmam que essa conquista deve ser feita de forma pacífica e democrática (Fundação Thiago de Moraes Gonzaga, s. d.).

Com base nos argumentos ora levantados, nos quais se analisam as implicações históricas, sejam elas midiáticas, sejam legislativas, governamentais ou nãogovernamentais, de políticas relacionadas ao consumo de álcool e sequente direção automotiva, se torna flagrante a relevância de investigar um viés de uma política pública que se destaca, a saber: o Programa Vida Urgente ES. Esse trabalho objetiva, portanto, identificar e analisar, por meio da Teoria das Representações Sociais, as representações dos jovens voluntários do Programa Vida Urgente de Vitória, Espírito Santo, acerca do trabalho desenvolvido por eles.

\section{Método}

\section{Participantes}

Participaram 20 voluntários do Programa Vida Urgente do Espírito Santo, divididos em dois grupos. No grupo 01 (G1) foram entrevistados 10 jovens com tempo de atuação no programa de 06 meses a 01 ano e no grupo 02 (G2) foram entrevistados 10 jovens que atuam no programa Vida Urgente há mais de 01 ano. O participante mais novo possui 15 anos e o mais velho 26 anos, em um total de 14 mulheres e 06 homens, residentes na Grande Vitória, sendo que ambos os grupos contavam com 7 mulheres e 3 homens.

Apesar de no site constar a informação de que há mais de 3.000 voluntários inscritos, restringimos o número de participantes por aquele não corresponder ao número de voluntários ativos. $\mathrm{O}$ ato de se inscrever pelo site e preencher um cadastro automaticamente inclui a pessoa no número de voluntários, o que não significa exatamente estar "na ativa". Pelo site, não há controle ou algum indicativo que demonstre que a pessoa participa ou não das ações. Os participantes foram selecionados pelos coordenadores do Programa de forma aleatória, do cadastro de voluntários ativos (que participaram de mais de 3 ações nos últimos dois meses), atendendo à condição da pesquisa de possuírem pelo menos mais de seis meses de voluntariado. Partindo do princípio que a seleção não foi realizada pelos pesquisadores, não se pode afirmar se houve viés no processo de escolha. A divisão dos participantes em dois grupos foi realizada com objetivo de verificar possíveis mudanças de relato sobre a ação no Programa. O número de entrevistas realizadas foi considerado satisfatório, uma vez que se observou entre os 20 participantes considerável grau de repetição em suas respostas, o que não acrescentava informações novas à pesquisa.

\section{Instrumento}

Foi desenvolvida uma entrevista para os voluntários com 13 questionamentos sobre a experiência pessoal dos participantes baseada na atuação no Programa Vida Urgente. As questões foram norteadas por cinco eixos: 1) os motivos pelos quais jovens inscrevem-se para o voluntariado, 2) a vivência por que passam, 3) a opinião sobre os efeitos da própria atuação, 4) a posição em relação ao consumo de bebidas alcoólicas e direção e 5) a visão que possuem do Programa.

\section{Procedimento de coleta de dados}

Utilizamos como instrumento de coleta de dados um roteiro de entrevista semiestruturado que objetivava colher informações tanto a respeito do funcionamento do Programa Vida Urgente quanto sobre como os voluntários compreendem sua atuação. As entrevistas foram realizadas em ambientes escolhidos pelos participantes, tendo sido 7 delas dentro da sede do Programa Vida Urgente e as outras 13 em salas reservadas do Núcleo de Psicologia Aplicada (NPA) da UFES. Todas as entrevistas foram previamente agendadas de acordo com a disponibilidade de cada entrevistado e tiveram duração média de 20 minutos. Todos os participantes assinaram o termo de consentimento, no qual os objetivos deste estudo estavam explicitados, além da garantia do sigilo das identidades dos entrevistados. No caso do participante menor de idade, solicitou-se a um dos responsáveis legais que autorizasse a participação no estudo.

As entrevistas foram transcritas e devolvidas aos participantes para eventuais mudanças de conteúdo e aceite. O conteúdo dessas só foi analisado após esse processo, seguindo orientações éticas para pesquisa em ciências humanas e sociais.

\section{Procedimento de análise dos dados}

Para a análise dos resultados, foi utilizada a análise de conteúdo, técnica defendida por Bardin (1994), cujo entendimento é que esse procedimento não deve ser utilizado apenas para proceder a uma descrição do conteúdo das mensagens, mas sim a interpretação daquilo que emerge da fala dos sujeitos. Para tanto, foram criadas categorias referentes às respostas conforme discussão a seguir. 


\section{Resultados}

Em razão do volume de dados, realizamos um recorte para fins desta publicação, seguindo os objetivos especificados. Sobre a forma como os participantes souberam do Programa Vida Urgente sediado no Espírito Santo, interessava-nos saber que meios (amigos, mídia, ações noturnas ou diurnas) foram destacados pelos jovens voluntários para o conhecimento do programa. Percebemos que, tanto no G1 quanto no G2, a maioria dos jovens possuía amigos que já eram voluntários $(60 \%)$ e isso foi um facilitador na divulgação do programa. A mídia aparece em segundo lugar $(30 \%)$ e as ações/abordagens em terceiro $(10 \%)$.

Por amigos, alguns já participavam do programa, né? Ai eles me chamaram para conhecer, porque ficavam falando que era legal e tal, ai en fui. (Participante 03, G1, sexo feminino, 18 anos)

Eu vi na TV. Não conhecia ninguém que faz̧ia parte do programa e eu vi a propaganda na TV. (Participante 07, G2, sexo feminino, 20 anos)

Sobre os motivos que levaram os jovens a ingressarem e permanecerem no programa, tanto no G1 quanto no G2, observamos respostas focadas na questão do voluntariado. Para esses jovens, ser voluntário está relacionado a "ajudar o próximo" e "sentir-se útil" para a sociedade. Questões como "mudar a sociedade" e a forma de abordagem do projeto aparecem em algumas falas. $\mathrm{O}$ voluntariado, ao mesmo tempo em que é representado como trabalho, é um trabalho carregado de representações positivas socialmente por parte desse grupo de entrevistados.

Eu acho muito legal, assim, pegar um pouco do seu tempo para fazer isso e tentar mudar essas pessoas que dirigem e bebem. E é isso, que a vida continua. (Participante 08, G1, sexo feminino, 19 anos)

Eles falam: "você pode fazer o que você quiser, é só você ter responsabilidade." Então, essa visão de não proibir, mas de orientar, de uma forma descontraida. Sabe? De jovem para jovem, de um jeito mais aberto, menos formal. Isso en gostei bastante, poder ajudar, poder fazer alguma coisa (Participante 03, G2, sexo feminino, 18 anos)

Em relação à forma como os jovens participam das ações do Programa Vida Urgente, percebeu-se no G1 e G2 que todos eles já passaram por abordagens na praia, por ações teatrais, abordagens noturnas ou mesmo em conjunto com o Programa Madrugada Vivai. Apenas um participante desse grupo relatou uma experiência no sentido do planejamento e não somente na execução das atividades desenvolvidas.
Eu trabalho como voluntário, abordo as pessoas, faço teatro mudo na praia, que mostra como a pessoa não deve se comportar, a gente faz tudo errado para mostrar que não deve fazer. Minha ação é mais no Vida Urgente na praia, mas vou também no Madrugada Viva, Vida Urgente no rock, blitz do Vida Urgente, vou em todos praticamente. (Participante 07, G2, sexo feminino, 20 anos)

[...] en já, fiz o workshop que é onde a gente senta, realiza uma ação, cria uma ação em si. (Participante 01, G2, sexo masculino, 18 anos)

Observa-se na fala dos participantes de ambos os grupos que a questão da conscientização está além das ações do programa. Metade dos entrevistados afirma que o que se aprende dentro do programa se leva para a vida e que cada um decide se esse aprendizado será transmitido às demais pessoas de seu círculo social, o que pode levar a um envolvimento para além do programa em si, ou seja, uma apropriação do ideal do projeto:

[...] mas o que en faço aqui, o que en faço nas ações, en faço com os meus amigos, então eu sou voluntária do Vida Urgente sempre. Não é porque eu não estou participando de ação que eu não estou trabalhando. É uma coisa para vida mesmo. (Participante 07, G2, sexo feminino, 20 anos)

Quanto à reação do público-alvo ante a aproximação dos voluntários verificou-se, no G1 e também G2, que $70 \%$ das respostas indica que o público-alvo admira e respeita o trabalho e os outros $30 \%$ deles alegam que a maioria do público prefere não participar ou valorizar a ação.

A maioria é muito receptiva, te dão atenção. A gente nunca chega impondo, mandando, obrigando ninguém a ouvir, a gente pede licença, pergunta se pode falar, se pode dar um recado. Geralmente são muito receptivos, gostam e admiram nosso trabalho. (Participante 02, G2, sexo feminino, 21 anos)

Tem vários tipos diferentes, tem aqueles que cacoam, tem uns que estão embriagados, mas a maioria felizmente, hoje em dia, já está recebendo melhor o projeto. (Participante 06, G1, sexo feminino, 21 anos)

Sobre a experiência de beber e assumir a direção automobilística, não houve relato dos participantes que confirmasse essa prática. Doze deles $(60 \%)$ não dirigem ainda. Cinco $(25 \%)$ não têm o hábito de consumir bebida alcoólica. Três participantes $(15 \%)$ fizeram uso das duas justificativas já apresentadas (não dirigem e não bebem). Vale destacar a fala de um participante que, apesar de não beber, atua conscientemente se vai andar de carona com alguém e que, assim como seu grupo de amigos, opta por um 
esquema de rodízio. O participante alega, ainda, que isso se deve também à necessidade de apresentar comportamento exemplar, uma vez que é voluntário do programa.

Levando em consideração ambos os grupos, quando questionados sobre já haver embarcado em caronas com motoristas alcoolizados, $90 \%$ afirmou já ter vivenciado tal experiência antes de entrar no programa, sendo que os únicos $10 \%$ que responderam de maneira negativa correspondem ao G2. Outro dado relevante é que $40 \%$ do G1 e $40 \%$ do G2 afirmaram que pegaram carona com parentes próximos alcoolizados $(37,5 \%$ pai, $25 \%$ tio, $12,5 \%$ cunhado, $12,5 \%$ sogro, $12,5 \%$ não especificado, todos do sexo masculino). Em relação à sensação ou sentimento que os participantes experienciaram no momento da carona com motorista sob efeito do álcool, 30\% do G1 relata ter sentido insegurança e $20 \%$ relata ter sentido medo e classifica a experiência como horrível. Já no G2, 60\% não especificou o sentimento e $40 \%$ disse ter sentido medo.

Era crucial saber se, na opinião desses jovens, houve alguma mudança no comportamento do motorista, no que diz respeito ao comportamento de beber e dirigir, após a "Lei Seca" ter entrado em vigor, isso porque a referida Lei foi implementada 1 ano após o início das atividades do Programa Vida Urgente. Quando questionados acerca do assunto, os participantes de ambos os grupos se manifestaram de maneira unanimemente positiva à mudança, tal como observamos no relato abaixo:

[...] hoje você vê grupos que fazem rodízio, um fica tomando suco e o resto bebe. Ou os caras sempre levam as namoradas on as esposas, elas sempre ficam sem beber, então essas são as pessoas que têm um nivel de consciência, que antes da Lei Seca elas já sabiam o quanto podiam consumir e consumiam aquela quantidade que era permitida. (Participante 08, G2, sexo masculino, 23 anos)

Entretanto, é imprescindível destacar que há o reconhecimento de que algumas pessoas, as que possuem carteira de habilitação há mais tempo, têm dificuldade de mudar o comportamento de beber e dirigir justificando que "dirigem melhor quando bebem" ou que "nunca aconteceu nada". Quanto às justificativas dos que responderam que houve mudança, a que mais se destacou no G1 foi que, embora o comportamento tenha mudado, quando a fiscalização diminui os motoristas deixam de se preocupar com a Lei $(40 \%)$. Há o reconhecimento de que só a Lei não basta para mudar o comportamento, que são necessárias medidas concomitantes de educação, controle e punição para que, paulatinamente, o comportamento preventivo seja adotado pela sociedade em geral e não somente pelo motorista. Já no $\mathrm{G} 2,50 \%$ dos participantes destacou a preocupação dos motoristas com a questão financeira, ou seja, o valor de multa, que parece ser um fator preponderante na decisão de não consumir bebida alcoólica antes de dirigir.

É perceptível que, apesar dos relatos dos voluntários referentes a avanços promissores em relação ao comportamento do motorista, no que concerne à associação entre bebida alcoólica e direção, são muitas as dificuldades para dar um novo contorno a representações sociais tão enraizadas quanto as que banalizam os efeitos da ingestão de bebida alcoólica no organismo. Negligenciam-se, portanto, efeitos característicos, descritos por Marques (2006), como diminuição de habilidades cognitivas e motoras, como a percepção e a coordenação, essenciais para que se possa assumir a direção de um veículo de maneira adequada.

É interessante observar aqui a complementaridade entre ações de teor coercitivo, como a Lei Seca, e uma abordagem similar à Política de Redução de Danos, no caso, as ações do Programa Vida Urgente. As duas formas de intervenção podem ser vistas como complementares às limitações da outra. Por um lado, a Lei Seca busca evitar as consequências prejudiciais dos acidentes de trânsito, cuja causa está relacionada à ingestão abusiva de bebida alcoólica, de maneira mais pontual e, por outro, o Programa Vida Urgente atua no sentido de promover mudanças em concepções e comportamentos, apostando em um processo que se dá em longo prazo, por meio da educação.

A respeito de onde entram as ações do Programa Vida Urgente no contexto da combinação entre o consumo de álcool e direção automotiva, constata-se que as ações estão inseridas no âmbito educacional por conta da transmissão de conhecimento, valores e informações, itens que permeiam as ações do programa. Essas também contribuem para que as pessoas cumpram os requisitos legais voltados para a redução dos prejuízos resultantes do ato de dirigir embriagado.

Sobre a mudança de comportamento das pessoas que são abordadas, as respostas dadas pelos participantes apontam para dois tipos de mudanças. O primeiro, é a mudança cultural, que ocorre de forma que os valores e práticas sociais sejam alterados em longo prazo. Os motoristas tornam-se gradativamente mais conscientes dos prejuízos de dirigir após a ingestão de álcool e passam a comportar-se de forma preventiva, praticando atitudes que promovam segurança própria e de seus caronas de forma mais natural e não apenas por coerção legal. 
O segundo tipo de mudança de comportamento das pessoas ao serem abordadas, para o qual as respostas apontam, é de caráter imediato, ainda no contexto da própria abordagem ou gerado a partir desta. Ocorrem mudanças positivas, como curiosidade sobre o voluntariado e interesse sobre o programa, sorrisos e agradecimentos, afirmação de que se estiverem bebendo não irão dirigir e que usarão o cinto de segurança. Algumas mudanças de caráter imediato são notadas por meio da observação da postura das pessoas, principalmente pela fisionomia e pelo discurso dos abordados. O contato pessoal direto possibilita que os voluntários analisem esses fatores no contexto da abordagem e julguem se a intervenção foi eficaz ou não e se os efeitos esperados ocorreram, tal como aponta a fala abaixo:

Algumas pessoas ficam curiosas, mas a maioria que está bebendo e sabe que vai dirigir fica sem graça e notamos isso na própria expressão facial do motorista da vez e inclusive a fisionomia nos caronas. (Participante 07, G1, sexo masculino, 21 anos)

Os participantes relatam algumas posturas, percebidas por eles como negativas, tais como as afirmações relativas a "pessoas apenas ouvem e em seguida descartam a mensagem", "ficam incomodados com a abordagem" ou "recebem os voluntários de forma negativa". Mesmo assim, os voluntários relatam não deixar que somente esse tipo de respostas afete o andamento das ações e consideram a ambivalência como meio de ratificar a existência do Programa Vida Urgente.

Em relação à presença de críticas e sugestões, no G1 e G2, mais da metade dos participantes (55\%) relatou não ter críticas ao programa, elogiando-o por ser acolhedor e preocupado com os voluntários. $\mathrm{Na}$ pequena parcela que relatou ter críticas $(20 \%)$, pode-se observar que estas não estavam diretamente relacionadas à proposta do programa, mas a outros voluntários e aos coordenadores.

\section{Discussão}

A receptividade positiva pela maioria do público-alvo do programa é um indício de que a forma como a problemática do consumo de álcool e seqüente direção automotiva é representada socialmente está sendo modificada, reconstruída. Em anos anteriores, o discurso de conscientização em relação à aquisição de posturas preventivas e responsáveis no trânsito se dava de forma tímida, mas atualmente, grande parcela da população tem demonstrado identificar-se com esses comportamentos, como pudemos perceber pela fala dos entrevistados. $\mathrm{E}$ isso se dá, pelo fato de que novas representações sobre a questão do álcool e direção automotiva foram incorporadas por parte da sociedade.

A mídia, por exemplo, ao fornecer informações diárias sobre os acidentes de trânsito, principalmente envolvendo jovens alcoolizados, é importante ator no processo de divulgação, tanto dos acidentes quanto das ações preventivas, educativas e punitivas. Dessa forma, a mídia televisiva ou impressa acaba por chamar atenção da sociedade para esse problema, para as representações existentes quanto ao ato de beber e dirigir e para as possíveis alternativas encontradas pelo poder público na solução da questão ora apresentada.

O Programa Vida Urgente, apesar de ser uma organização não-governamental (ONG) iniciada no Rio Grande do Sul, assume características, no Espírito Santo, de poder público. Desse modo, o programa é financiado por dinheiro público, proveniente de parte das multas de trânsito. Como esse programa não é previsto pelo CTB ou por nenhuma lei, e tem caráter local, trata-se de uma política de governo que pode ser alterada juntamente com o início de mandato do próximo governador do Estado e, dessa forma, depende do interesse e do jogo de forças dos diversos atores sociais para sua continuidade.

Observa-se, nesse contexto, que o voluntariado é valorizado enquanto "arma ideológica" pelos entrevistados. Tal como afirma Carballal (2009), o voluntariado aparece no cenário mundial, principalmente em países europeus, como uma forma complementar de atuação do Estado, nas políticas em que o mesmo não pode ou não quer operar, terceirizando-se fazeres. A reflexão que ora se apresenta mostra que o Programa Vida Urgente no Rio Grande do Sul era propriamente uma ação do terceiro setor. Quando o mesmo programa é implementado no ES, não perde as características de uma ONG, ao mesmo tempo em que se torna uma apropriação estatal, mantida e coordenada pelo governo.

A determinação de todos aqueles que se envolvem com o Programa Vida Urgente, buscando propagar uma mensagem de valorização à vida, é louvável, entretanto, ainda é cedo para apontar se os resultados obtidos pelo Programa correspondem àqueles a que se propõe. A pesquisa aqui presente configura-se como um primeiro passo. Faz-se necessário um esforço relativamente maior, que deveria ser conduzido na direção de uma análise mais profunda da repercussão que as intervenções realizadas alcançam e de seus impactos para a sociedade. 


\section{Referência}

Bardin, L. (1994). Análise de conteúdo. Lisboa: Edições 70.

Brasil (2006). Resolução CONTRAN n. 206 de 20 de outubro de 2006. Obtido em 17 abril de $2010 \mathrm{da}$ world wide web: http:// www.denatran.gov.br/download/Resolucoes/Res olucao206_06.pdf.

Brasil (2008). Lei Presidência da República n. 11.705 de 19 de junbo de 2008. Obtido em 22 de junho de 2010 da world wide web: http://www.planalto.gov.br/ccivil_03/_Ato20072010/2008/Lei/L11705.htm.

Carballal, L. B. (2009). El voluntariado: entre la ciudadanía y la ideologia. Revista Katálysis. Florianópolis, 2(2), 235-240.

Fundação Thiago de Moraes Gonzaga .(2010). Fundação, histórico. (s.d.). Obtido em 03 de maio de 2010 da world wide web: http://www.vidaurgente.org.br/site/int_fundacao -secao.php?secao $=$ historico.

Jodelet, D. (2001). Representações sociais um domínio em expansão. Em D. Jodelet (Org.). As Representações Sociais (pp. 17-44). Rio de Janeiro: EdURJ.
Jovchelovitch, S. (1994). Vivendo a vida com os outros: intersubjetividade, espaço público e Representações Sociais. Em S. Jovchelovitch \& P. Guareschi (Orgs.). Textos em representações sociais (pp. 63-83) Petrópolis, RJ: Vozes.

Marques, A. C. (2006). As marcas do álcool na saúde: propostas. Obtido em 22 de junho de 2010 da world wide web: http://www.ippad.com.br/ippad/site/principal/ material.asp?var_chavereg $=153$.

Masur, J. (2004). O que é alcoolismo? São Paulo: Brasiliense.

Matos, M. I. S. (2000). Meu lar é o botequim: alcoolismo e masculinidade. São Paulo: Ed. Nacional.

Nascimento, A. \& Garcia, M. L. (2009). Álcool e direção: uma questão na agenda política brasileira. Psicologia e Sociedade, 21(2), 213-222.

Stronach, B. (2004). Álcool e redução de danos. Em E. Burning, M. Gorgulho, A. G. Mecop \& P. O'Hare. (Orgs.). Álcool e redução de danos: uma abordagem inovadora para países em transição. Brasília: Ministério da Saúde.

Sobre os autores:

Recebido em 09/08/2010

Reformulado em 14/03/2011

Aprovado em 22/06/2011

Andréa dos Santos Nascimento é doutoranda em Psicologia pelo Programa de Pós-Graduação em Psicologia UFES e bolsista FAPES.

Davi Manzini Macedo é graduando em Psicologia e bolsista do Programa de Educação Tutorial de Psicologia da UFES.

Julia Carolina Rafalski é graduanda em Psicologia pela UFES.

Lorena Dias de Abreu é graduanda em Psicologia pela UFES e bolsista de iniciação científica pela FACITEC.

Mayara Gama de Lima é graduanda em Psicologia e bolsista de iniciação científica pela UFES.

i Programa implementado pelo Departamento Estadual de Trânsito do ES desde 2003. 